terior to the median line of the transverse axis, and split it both ways in the direction of the long axis, as is commonly the case with the present conical balls. All the fragments now being removed, some of my unbelieving Turks again examined it, and confessed there was an arch of continuity. I passed a drainage-tube through the limb, and stuffed the wound with lint dipped in carbolic oil. I also put on splints to keep the limb at perfect rest, and used sandbags to steady it when the patient was in bed, at the same time keeping up extension by means of the American stirrup. The patient's temperature went up a little for a few days, but otherwise he had no bad symptoms. Callus was thrown out, and the wounds closed up. About seven weeks after the operation the man was able to walk out of the hospital by the aid of a crutch, and I had the pleasure of letting the Turkish surgeons see him. There was about an inch and a half of shortening, due to muscular contraction.

I select this case from among many others as being, I think, especially interesting, amputation being recommended in these cases by most writers.

\section{CAPSICUM IN EXTREME CASES OF DELIRIUM TREMENS.}

BY BINGHAM CROWTHER, L.R.C.P.L., \&c., HOUSE-SURGEON TO THE GENERAL HOSPITAL, HOBART TOWN.

THE two cases I am about to mention will prove that we have in tincture of capsicum a most valuable remedy in dangerous cases of delirium tremens, and its action in the second case (complicated with pneumonia) points to a new line of treatment for that affection, for pneumonia occurs in this country chiefly in individuals who have been subjected to lowering agents (hard work, cold, wet, \&c.) It must be owing to its stimulating and derivative effects that capsicum is of value both in the delirium tremens cases and in the pneumonic complication. It will be noted that capsicum acted in many ways in common in both the cases I am about to mention. First, the rapidity of its action, reducing all the tremor and agitation (in a few hours), followed by a calm and prolonged sleep. Second, the skin, from being clammy, is soon restored to its natural warmth, and perspires freely. Third, the pulse, which before its use is 140 to 150 , rapidly falls to 100 , and instead of being small and compressible, regains its fulness and volume. Fourth, both the kidneys and bowels act freely, large quantities of urine being passed frequently, and the alvine evacuations in large quantities (the bowels being continually relaxed whilst taking the capsicum). It must be to its derivative action that the brain so rapidly becomes tranquil. All these actions were well marked in the cases $I$ am about to relate, and they seem, both from their therapeutical and physiological points of view, to be typical of the known action of capsicum.

CASE 1.—G. E-, aged forty-eight, admitted April 3rd, 1878. Is tall, fair, and well built, and for several nights has been without sleep. History of being a heavy drinker, chiefly of spirits. All the known ordinary remedies had been tried by his surgeon prior to admittance; the case becoming extreme necessitated his removal here. (The same patient was under treatment for three days in January, 1878, in a similar condition. Bromide of potassium, ten grains every four hours for two days, failed to relieve; and tincture of digitalis, in three doses of three drachms every four hours, produced a sound sleep and rapid recovery.) On admission he is constantly moving about, talking all sorts of rubbish, giving orders, \&c., with much muscular tremor. $\mathrm{He}$ answers some questions rationally when spoken to. Pulse 140, weak and compressible. Tincture of digitalis ordered in three doses of three drachms each, erery four hours at night.-April 4th: No relief whatever; is in a similar condition to yesterday. Palse 150 , very weak and compressible. No sleep.-5th: In the same condition, but worse, so weak he cannot stand, and seems in great danger of death from asthenia. Ordered tincture of hyoscyamus combined with bromide of potassium, but no relief taking place in twelve hours (he had taken four doses of the latter mixture), half a drachm of tincture of capsicum in half an ounce of water was given every three hours. - 6th : Has slept since 4 A.M., and now (10.30 A.M.) is still resting. Pulse 110, full ; respi- ration 24 , easy; bowels opened freely through the night the urine has been passed frequently and in large quantity. -8th : Continues to improve ; frequent micturition; bowels open two or three times daily.-10th: Discharged well Nearly all tremor had left. Sleeps well during both night and day. Has a firm, full pulse, and is very grateful for his rapid recovery. Diet strong slops, with a pint of double beef-tea, porter, and other nourishing food.

CASE 2.- Robert C-_ aged thirty-six, admitted June 23rd, 1878. Patient is tall, dark, and well built; has been employed as drayman for seven years. Has been exposed to changes of weather, and enjoyed good health until six weeks ago, when he got wet. Pains all over body followed. Has been accustomed to take large draughts of beer, especially when heated, also at other times, more so lately. Four days before admittance called in a doctor, who found him suffering from delirium tremens, and ordered his removal here. On admission patient had marked delirium tremens, with hallucinations (driving horses, \&c.) Breathing natural Pulse 130, soft compressible. Answers questions in a jerk ing, tremulous way, not very distinctly. Ten grains of bromide of potassium ordered every four hours. - June 24th Worse ; is constantly moving about, although put to bed several times. No sleep since admittance. Pulse 140, very compressible; skin clammy; bowels have not acted yet. Has a dry cough. Condition one of danger. A mixture of tincture of capsicum with brandy and egg was given every four hours. After taking first dose he fell into a calm sleep, and remained in that condition until afternoon.25th: His cough is worse ; also short breathing and rusty sputa attracted attention, and on examination he was found to have crepitation over whole of right lung. Respiration 45 ; pulse 140. (Pneumonia.) Passed much urine, and bowels have twice been opened during the evening. Skin warm, freely perspiring. Delirium abated. Transfer in the afternoon from the cells to general wards.-26th : Bronchial breathing and bronchophony over whole of right lung, and increased tactile vibration. - 27th: Is worse. Pulse 140; respiration 50. Delirium again returning. Both urine and motions have passed freely daily. Skin very hot and perspiring. -28th : Is violently delirious, although quiet when spoken to. Had an attendant all last night, and to-day was obliged to be again removed to a special ward. Life despaired of. Pulse 120; respiration 45. His capsicum mixture (which had been taken regularly) was now halved, and taken every six hours.-29th: Delirium subsided. Patient feels comfortable, and has much improved. Crepita. tion in lower half of right chest, rest of chest same as on 25th. Pulse full, 110. Takes his food and sleeps well. Alvine and urinary secretions continue free.-30th: Improvement continues. Respiration 36; pulse 100.-July 4th: His right chest has gradually resolved itself into a healthy condition, no abnormal sounds being heard. Is rapidly convalescing. Pulse 85 ; respiration 20 . The diet has been nourishing; slops in a concentrated form, with two pints of ale (which latter was changed on the 28th for porter). Small doses of spirit of nitrous ether and carbonate of ammonia were combined with the mixture during the pneumonia.

\section{ON THE SURGICAL TREATMENT OF ANASARCA.}

By H. A. WICKERS, M.R.C.S., L.R.C.P. LOND., LATE HOUSE-PHYSICIAN TO CHARING-CROSS HOSPITAL.

THE treatment of anasarca, whether cardiac or renal in its origin, after ordinary therapeutic measures, such as diuretics, purgatives, \&c., have failed, is, in many instances, very unsatisfactory. If the patient be let alone he rapidly gets waterlogged and dies; incisions or punctures nearly always lead to sloughing, while other plans of treatment have proved scarcely less unsuccessful.

The following method has been in use at Charing-cross Hospital for some months; it has been found to increase the patient's comfort considerably, while in no instance has it been followed by ulceration, sloughing, or cutaneous inflam. mation; it appears, indeed, to substitute a perfectly safe means of getting rid of the fluid for those which have hitherto been attended by much risk. 
The legs having been well oiled, and a macintosh sheet placed under them, about twenty or thirty punctures are rapidly made in their sides with a stout straight needle or hare-lip pin, care being taken that the needle is passed deeply into the subcutaneous cellular tissue. Some sponges which have been well wrung out in a solution of salicylic acid are now placed against the punctures, so as to absorb the dropsical fluid as it transudes; these sponges as they become saturated are squeezed out, and again passed through a solution of salicylic acid before being replaced against the patient's skin. In this manner renewals may be required every two or three hours, and several pints of fluid may be drained away during the first twenty-four hours, the whole process being possibly completed in four or five days, at the end of which time the punctures are usually healed.

By the use of salicylic acid in the manner described, decomposition of the transuded fluid is obviated, the sponges are kept free from fetor, the skin is not irritated, and cutaneous inflammations of a low type, with their attendant evils, are entirely prevented.

\section{g a dithror}

\section{HOSPITAL PRACTICE, BRITISH AND FOREIGN.}

Nulla autem est alia pro certo noscendi via, nisi quamplurimas et morborum et dissectionum historias, tum aliorum, tum proprias collectas habere, et inter se comparare.-Morgagni De Sed. et Caus. Morb., lib.iv. Procomium.

\section{MIDDLESEX HOSPITAL.}

A SERIES OF CASES OF FRACTURE OF THE SKULL. (Under the care of Mr. HuLkE.)

THE two following cases, like that reported at p. 50, show the supervention of high temperature on fracture of the skull, unassociated with any appreciable signs of inflam. mation.

CASE 2. Fracture of temple and anterior fossa of base of skull; great elevation of temperature.-At 8.55 A.M. on April 7th, 1875, a pianoforte-maker was admitted into Broderipp ward insensible, cold, and nearly pulseless; his pupils were contracted, and his face much bruised and grazed. No fracture or bruise of the head could be felt. An hour later his breathing was laboured, his cheeks sinking and puffing out during inspiration and expiration. His left forearm was rigidly flexed. He moaned and ground his teeth, and was convulsed. On the 8 th he was unconscious, often moaning; limbs rigid. On the 9th the breathing was shallow; coarse râles all through chest. Temperature $104^{\circ}$. Later in the day it reached $105^{\circ}$. He died at 10 P.M. Necropsy. - Blood was extravasated on and into the right temporal muscle. A fissure started from the temple, and crossed the orbital plate of the frontal bone into the ethmoid, the cells of which, together with the apex of the orbit, were filled with extravasated blood. There was a thin film of blood-clot under the dura mater along the line of the crack, and a very extensive clot on the lateral surface of the right cerebral hemisphere, with much bruising of brain there.

CASE 3. Fracture of skull; death; extensive homorrhage between the dura mater and bones; very high temperature. A large, heavy brewer, aged twenty-eight, was admitted in to the hospital at 4 A.M. on Nov. 24th, 1877. He was said to have gone home drunk about three hours before, to have gone to sleep in a loft, and about two and a half hours later to have risen and fallen from the loft on to a floor paved with pebbles, a depth of fourteen feet. When admitted, he was quite unconscious; pulse 60 , respiration 30 per minute. The right ear was torn at its insertion, and the scalp over this was grazed, but no fracture could be felt. At 10.15 A.M. the breathing was laboured; pupils unequal, the right being dilated; conjunctiva of right eye red; pulse 100. At 11 he voided urine into the bed. At 2 P.M. the pulse was 100 , respiration 36 , temperature $105 \cdot 4^{\circ}$. At 2.15 the catheter was passed; urine acid, sp. gr. 1025, and contained a trace of albumen. At 3.15 the pulse was 100 , respiration 32 , temperature $105.8^{\circ}$. At 3.30 he died.
Necropsy. - A fracture was found starting from the right parietal bone, crossing the squamous portion of the temporal and the sphenoid, and ending in the sphenoidal fissure. One of the large branches of the middle meningeal artery had been opened, and a clot of the size of a half orange was found between the dura mater and bones. The convolutions of the under-surface of the left hemisphere bounding the Sylvian fissure were bruised.

\section{ST. LEONARD'S HOSPITAL, SUDBURY, SUFFOLK. \\ CASES OF CHOREA.}

Fon the following notes we are indebted to Dr. J. Sinclair Holden.

CASE 1. Chorea complicated with rheumatic fever and spinal irritation; recovery.-G. $\mathrm{H}-$, a delicate-looking lymphatic boy, aged eleven years, was admitted with the following history and symptoms:-Two weeks before admission he was taken ill with rheumatic fever, and during the acute course of the disease chorea commenced. Becoming very restless and violent, the boy was sent into the hospital. The symptoms on admission were rheumatic swelling and pain in both wrist-joints ; slight systolic bruit; temperature $103 \cdot 5^{\circ}$. The choreic movements were violent and erratic over the whole body, except the inflamed wristjoints, which he kept quiet. The head, eyes, and mouth, particularly, were in incessant motion. In addition to the ordinary choreic movements, there were frequent paroxysms of muscular rigidity along the course of the spine, quite tetaniform in character, even to distinct opisthotonos. There was no true trismus, yet a stiffness about the mouth delayed his opening it, and when open it closed with a snap; articulation was most difficult, but he swallowed with ease; dysuria also existed. The treatment for the first few days was salicin and bromide of potassium. On the fourth day he had copious perspirations, followed by a miliary eruption; the wrist-joints were better; temperature $100^{\circ}$; but there was no improvement in the choreic movements or rigidity of back. He was now placed under chloral, and its influence maintained more or less for four days, twelve grains three times a day being sufficient. $\mathrm{He}$ slept quietly without movements, taking liquid food and stimulants freely at regular intervals when partially awake. The result of the chloral treatment was a marked improvement in the choreic, but very little in the tetaniform symptoms. These slowly and gradually subsided under arsenic treatment and nourish. ing diet. He was seven weeks in hospital, and though free of the chorea when he left, there was still some stiffness in the muscles of the back and neck, which was not rheumatic.

CAsE 2. Severe chorea treated by chloral hydrate and arsenic; cure. - A girl of sixteen, tall and robust-looking for her age, was admitted with chorea of three months' standing, and which had originated in a fright. Her body, arms, and legs were covered with bruises from falls she had unfortunately experienced, owing to the violence of the jactitations and the want of care or restraint at her home. Treatment of various kinds had been tried, but failed to subdue the violence of the attack. On admission she was banked up between two beds (being jerked out of an ordinary bed in a few minutes), and placed under the influence of chloral. Before the effect of the first dose passed off, a smaller one was given, so as to ensure ten or twelve hours of sleep, as recommended by Dr. Robert Bridges. This was maintained for four days, with the result of completely breaking the severity of the attack, which then assumed the quieter form. She remained a month longer in hospital, gradually improving under arsenic treatment, and then was sent to the Felixstowe home, where she completely recovered.

CASE 3. Chorea; ether spray to spine; recovery.-A girl of nineteen had had several previous attacks. The left arm and leg constantly twisted and jerked, but the case was not violent enough for chloral. The usual tonics were tried, and produced no effect. She then had the ether spray applied along the spine, the skin being frozen at intervals of three inches. This was done every morning for five or six minutes. She began to improve after the first application, and in ten days was able to leave the hospital, cured, and take a situation as a servant. 